\title{
En Santiago de Chile ${ }^{1}$
}

\author{
Benoit Mathot \\ Doctor en Teología \\ Universidad Católica del Maule \\ bmathot@ucm.cl
}

Como citar este artículo: B. MATHOT "En Santiago de Chile” en Palabra y Razón. Revista de Teología, Filosofia y Ciencias de la Religión No15, Julio 2019, pp. 105-107 https://doi.org/10.29035/pyr.15.105

Presencia-ausencia de Dios

Mi experiencia de vida en Chile es relativamente corta. Estoy en este país junto a mi familia desde diciembre del 2016, sin embargo, este tiempo me ha permitido saber, como le ocurre a todo viajero que descubre Santiago de Chile, que el punto de referencia para los visitantes de esta ciudad es la "Alameda".

La Alameda es el nombre de la calle principal y se caracteriza por sus permanentes tacos. Atraviesa Santiago de poniente a oriente y es una línea recta que nada parece alterar, atravesando y vinculando diferentes universos urbanos que, en apariencia, resultan impermeables los unos a los otros y a los que, en principio, todo los opone. A lo largo de su recorrido, se pasa permanentemente de un mundo a otro: de los barrios pobres y populares instalados en el lado poniente de la ciudad a los sectores comerciales; de los barrios comerciales a los de las instituciones (universidades, Biblioteca Nacional, Museo de Arte Moderno, antiguas iglesias, así como el Palacio Presidencial "La Moneda", lugar simbólico del Golpe de Estado que le permitió a Pinochet hacerse del poder en 1993); finalmente, del barrio institucional al de los negocios, de los bancos y de las grandes empresas que se sitúan en los faldeos de la Cordillera de la Andes. Caminar por la Alameda hacia el oriente, que es como subir lentamente en dirección a la cordillera, consiste también en seguir un itinerario paralelo, el que se relaciona con ascender, simbólicamente, en la escala socioeconómica del Chile contemporáneo.

\footnotetext{
${ }^{1}$ Publicado originalmente en $A u$ coeur $d u$ monde 153-154 (2018-2019) P. 139-142. Traducción de Javier Agüero Águila.
} 
Ciertamente, caminar por las veredas de la Alameda es la experiencia concreta de enfrentar a una masa de gente que se atropella y choca, que no se mira (o solo furtivamente). Es tener la experiencia de música, de olores, de colores. Es, en último término, evitar caminar entre tejidos, objetos, artículos de todos los tipos que están en el suelo, y que en su mayor parte haitianos o venezolanos venden por unos cuantos pesos. Es, también, pasar a través el humo de las parrillas donde se asan carnes, pollos y choclos que los cocineros callejeros ofrecen a los transeúntes. Sin embargo, caminar sobre las veredas de la Alameda, lugar de pasaje y de tránsito es, también, y fundamentalmente, atravesar espacios heterogéneos, traspasar fronteras visibles y simbólicas y darse cuenta de golpe que se cambia de universo, que las personas con las que nos topamos se vuelven repentinamente otras, vistiéndose, hablando y viviendo de manera diferente.

Pero, en el fondo, es un sustrato de indiferencia el que parece estar instalado en el corazón del ciudadano-consumidor chileno, y este es el hilo conductor que ha tonificado mi experiencia en torno a estos contrates y a estos pasajes de un mundo a otro. ¿Es esto el efecto de la generalización del imaginario neoliberal? Entonces, es aquí, desde donde estoy parado, que se me exige caminar y buscar. Debo admitir que, teniendo una experiencia limitada en relación a la espiritualidad ignaciana, el sentimiento que prevalece en mí cuando recorro Santiago no es el de la presencia de Dios, ipor el contrario! No tendría de esta manera ningún sentido, para mí, el afirmar de golpe y de manera inmediata su presencia en la sonrisa contagiosa de los niños, iluminando la mirada siempre preocupada de los peatones, o en los gestos de solidaridad que, inevitablemente, animan toda vida en común. Al momento de escribir estas líneas, me parece más justo nombrar esta experiencia de ausencia y profundizar en ella. ¿Quizás podamos descubrir algo sobre Dios? Porque ¿cómo pensar que Dios mismo está ausente de una parte de lo real? ¿no es necesario, más bien, intuir que Dios es mucho más vasto que lo que yo puedo percibir de él? ¿no hay una presencia divina más sutil que la que yo creo poder discernir, reconocer, vivir? ¿quizás las huellas de Dios se encuentran frente a mis ojos, en la mirada cómplice intercambiada, en la relación que se establece con alguien, en una palabra, en la esperanza, o en las vidas destrozadas de todos aquellos transeúntes a quienes nada parece detenerlos? ¿no se trataría de vaciar mis expectativas, mi horizonte de espera? ¿de disponerme a la sorpresa?

El trayecto por las veredas de la Alameda, por el griterío caótico, entre esos miles de rostros que se cruzan sin verse, aparentemente indiferentes unos a otros, $y$ sobre todo a través de la evidencia escandalosa de las desigualdades que atraviesan a la sociedad chilena, me invita a una apuesta loca. ¿Cuál es esta apuesta loca? Pensar que más allá del trastorno causado por mi dificultad de percibir a Dios en todas las cosas, para retomar la expresión de San Ignacio, una presencia misteriosamente 
presente y activa trabaja -quizás- a pesar y más allá de mí, en el centro de lo real para hacerlo más justo y más humano.

En el fondo, lo que aquí está en juego en las congestionadas veredas de la Alameda, no es más que la oportunidad para una decisión de fe, a la que el teólogo protestante Paul Tillich nos invita a atrevernos pensando en "este Dios que surge cuando Dios ha desaparecido en la angustia de la duda". Un Dios en el cual se enraíza, paradojalmente, la experiencia de lo que denomina "el coraje de ser". Entrar en esta apuesta loca que va más allá de mí, significa confiar en una presencia que se da a pesar de mi incapacidad, a veces, para reconocerla. Entrar en la intimidad de Dios que está siempre.

"Dios más allá de Dios"2, citando nuevamente a Tillich. Es decir, más allá del Dios que yo busco, pero que se parece más una proyección de mí mismo que a ese otro que me convoca a una vida más humana, en comunión con mis hermanos y hermanas humanos. Entrar en esta decisión de fe es, quizás, el más hermoso descubrimiento que me regala un paseo por la Alameda.

${ }^{2}$ P. TILLICH. Le courage d'être, trad. J.-P. LeMay. Cerf: Paris; Labor et Fides: Genève ; PUL: Québec, 1999, p. 148. 